mellitus in patients taking $\mathrm{HCQ}$ at a cumulative dose $\geq 175 \mathrm{~g}$ was reduced $[\mathrm{HR}$ 0.60 (95\% Cl: 0.45 to 0.80$), \mathrm{p}<0.001$ ]. Higher prednisolone-equivalent dose $(\geq 88$ defined daily dose) was associated with increased risk of developing diabetes mellitus [HR 1.50 (95\% Cl: 1.11 to 2.03 ), $\mathrm{p}=0.001$ ], which was reduced by concomitant $\mathrm{HCQ}$ use at a cumulative dose $\geq 374 \mathrm{~g}$ [HR 0.34 (95\% Cl: 0.22 to 0.56 ), $\mathrm{p}=0.001]$.

Conclusions: This propensity score matched analysis of Taiwanese patients with primary SS found that use of $\mathrm{HCQ}$ is associated with reduced risk of incident diabetes mellitus in a dose-dependent manner. High-dose glucocorticoids increase the risk of diabetes, which can be decreased by concomitant HCQ use. Disclosure of Interest: None declared DOI: 10.1136/annrheumdis-2018-eular.5945

\section{OP0257 DECREASE OF AUTOPHAGY IN PERIPHERAL BLOOD MONONUCLEAR CELLS FROM SYSTEMIC LUPUS ERYTHEMATOSUS PATIENTS TREATED WITH BELIMUMAB}

T. Colasanti, F.R. Spinelli, C. Barbati, L. Massaro, F. Ceccarelli, M. Vomero, F. Morello, V. Orefice, F. Conti, G. Valesini, C. Alessandri. Lupus Clinic, Sapienza University of Rome, Rome, Italy

Background: Autophagy is a conserved catabolic process that degrades cytoplasmic constituents and organelles in the lysosome, promoting the recycling of cellular nutrients, and is also a key mechanism for protein homeostasis and quality control ${ }^{1}$

T lymphocytes from patients with systemic lupus erythematosus (SLE) are resistant to induction of autophagy ${ }^{2}$.

Belimumab (BLM), a human monoclonal antibody that inhibits B lymphocyte stimulator (BLyS), is the first biological drug to be approved for the treatment of SLE. BLM seems to play a role in modulating the signalling cascade involved in the regulation of autophagy, blocking the binding of soluble BLyS to its receptors (B cell activating factor receptor, BAFF-R; B cell maturation antigen, BCMA; transmembrane activator and calcium modulator and cyclophilin ligand interactor, $\mathrm{TACl}$ ), mainly expressed on B cells and plasmacells ${ }^{3}$.

Objectives: The aim of this study was to evaluate the autophagy process by means the expression of LC3-II and p62 markers in lysates of peripheral blood mononuclear cells (PBMCs) from SLE patients at baseline (t0) and after 2 weeks (t2weeks), 1 month (t1month), and 3 months (t3months) of treatment with BLM. We also investigated the presence of BLyS receptors on T cell subsets.

Methods: We enrolled 15 consecutive patients who started treatment with BLM $(\mathrm{M} / \mathrm{F}, 0 / 15$; mean age, 44.3 years, range $30-54$ years; mean disease duration, 242.6 months, range 48-432 months). All patients fulfilled the American College of Rheumatology revised classification criteria ${ }^{4}$. PBMCs from SLE patients were lysed in lysis buffer and analysed to evaluate autophagy, monitoring LC3-II and p62 levels by Western blot. Flow cytometry was performed for surface phenotyping of freshly isolated PBMCs, using conjugated monoclonal antibodies against human CD4 and CD8; anti-human BAFF-R, BCMA, and TACI polyclonal antibodies were used to detect BLyS receptors on T cells subsets.

Results: LC3-II expression levels in PBMCs from SLE patients decreased after 3 months of BLM therapy and, in the same lapse, p62 levels increased (figure 1; $\mathrm{p}<0.05$ for all the experimental conditions). BAFF-R and BCMA were expressed on $\mathrm{CD}^{+}$(Mean Fluorescence Intensity -fold increase-, MFI=1.6 and 1.2, respectively; $\mathrm{p}<0.05)$ and $\mathrm{CD}^{+}(\mathrm{MFI}=1.6$ and $2.5 ; \mathrm{p}<0.05) \mathrm{T}$ cells, while $\mathrm{TACl}$ was expressed only on $\mathrm{CD}^{+} \mathrm{T}$ cells $(\mathrm{MFI}=1.2 ; \mathrm{p}<0.05)$.
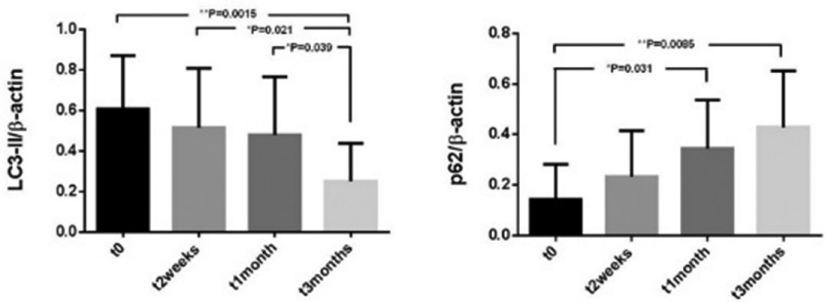

Conclusions: In the present study we demonstrated, for the first time, the expression of BAFF-R, TACl and BCMA in CD4 ${ }^{+}$and $\mathrm{CD} 8^{+} \mathrm{T}$ cells from SLE patients, and that BLM treatment was able to decrease the levels of autophagy in PBMCs. We can speculate that BLM could mediate this effect by blocking the binding of BLyS with its receptors.

\section{REFERENCES:}

[1] Kaur, Debnath. Autophagy at the crossroads of catabolism and anabolism. Nat Rev Mol Cell Biol 2015;16:461-72.
[2] Alessandri, et al. T lymphocytes from patients with systemic lupus erythematosus are resistant to induction of autophagy. FASEB J 2012;26:472232.

[3] Rockel, Kapoor. Autophagy: controlling cell fate in rheumatic diseases. Nat Rev Rheumatol 2016;12:517-31.

[4] Hochberg. Updating the American College of Rheumatology revised criteria for the classification of systemic lupus erythematosus. Arthritis Rheum 1997:40:1725.

Disclosure of Interest: None declared

DOI: 10.1136/annrheumdis-2018-eular.6237

\section{FRIDAY, 15 JUNE 2018 \\ From cartilage to bone}

\section{OP0258 EFFICACY OF THE HIGHLY SELECTIVE ADAMTS-5 INHIBITOR GLPG1972 IN THE RAT MENISCECTOMY MODEL}

L. Lepescheux ${ }^{1}$, P. Clement-Lacroix ${ }^{1}$, D. Merciris ${ }^{1}$, S. Meurisse ${ }^{1}$, M. Borgonovi ${ }^{1}$, C. Cottereaux ${ }^{1}$, P. Mollat ${ }^{1}$, F. Brebion ${ }^{1}$, R. Gosmini', F. De Ceuninck ${ }^{2}$, I. Botez ${ }^{2}$, E. van der Aar ${ }^{3}$, T. Christophe ${ }^{3}$, N. Vandervoort ${ }^{3}$, R. Blanqué ${ }^{1}$, D. Comas ${ }^{1}$, P. Deprez ${ }^{1}$, D. Amantini' ${ }^{1}$ 'Galapagos Sasu, Romainville; ${ }^{2}$ Institut de Recherches Servier, Suresnes, France, ${ }^{3}$ Galapagos NV, Mechelen, Belgium

Background: Aggrecan cleavage is an early process in cartilage degradation observed in OA. As a result, aggrecanase inhibition is an attractive therapeutic strategy for the treatment of OA. ${ }^{12}$ A disintegrin and metalloproteinase with thrombospondin motifs-5 (ADAMTS-5) is an aggrecanase playing a key role in the catabolic events leading to $\mathrm{OA}{ }^{3}$ We previously described the pharmacological characterisation of GLPG1972, a potent, selective and orally bioavailable ADAMTS-5 inhibitor showing anti-catabolic activity in cartilage explants and displaying disease-modifying OA drug (DMOAD) potential in the destabilisation of the medial meniscus (DMM) model in mice. ${ }^{4} 5$

Objectives: In this communication we report the activity of GLPG1972 in a second model of surgery-induced OA, the rat meniscectomy (MNX) model. ${ }^{6}$

Methods: OA pathology was induced by meniscectomy in the right hind leg of each rat. On day 1 post surgery, rats were randomly assigned to a treatment group ( $n=20$ per group) according to their body weight. GLPG1972 was administered orally over 3 weeks at dose levels of 10,25 and $50 \mathrm{mg} / \mathrm{kg}$ b.i.d. At sacrifice, the right tibias were collected and processed for histological analysis. OA development in the tibial plateau was evaluated using the OARSI score. The following structural parameters were measured by imaging histomorphometry analysis: subchondral bone plate thickness, proteoglycan content and fibrillation index Blood samples were collected at steady state at predose, 1, 3 and 6 hour postdose for the determination of GLPG1972 plasma concentrations.

Results: Three weeks post-surgery, a significant reduction in OARSI score compared to vehicle-treated rats was observed with GLPG1972 at 25 and $50 \mathrm{mg} / \mathrm{kg} \mathrm{b}$. i.d. ( $-24 \%$ and $-23 \%$, respectively). Treatment with GLPG1972 also resulted in a significant reduction in cartilage fibrillation as of $25 \mathrm{mg} / \mathrm{kg}$ b.i.d. and prevented proteoglycan loss and subchondral bone plate thickening at all doses. At $25 \mathrm{mg}$ kg b.i.d. GLPG1972 average plasma concentration over 24 hour was found to be in line with the value observed in other rat MNX experiments $(385 \mathrm{ng} / \mathrm{mL})$. GLPG1972 bio-distribution in the target tissue was also determined: the average condyle to plasma ratio was found to be 0.14

Conclusions: Oral dosing with GLPG1972 in rat MNX model resulted in significant chondroprotection confirming the DMOAD potential of GLPG1972. A Phase 1 first-in-human study was successfully completed with GLPG1972 (NCT02612246), and a dose-escalation Phase 1b study in OA patients is ongoing (NCT03311009). GLPG1972 is a promising OA drug candidate and a Phase 2 program is currently under preparation.

\section{REFERENCES:}

[1] Little CB, et al. J Clin Invest 2007;117:1627-1636.

[2] Larsson S, et al. Arthritis Res Ther 2009;11:R92.

[3] Fosang AJ. Osteoarthritis Cartilage 2015;23(8):1231-1232.

[4] Clement-Lacroix $\mathrm{P}$, et al. OARSI congress 2017

[5] Clement-Lacroix $\mathrm{P}$, et al. EULAR congress 2017

[6] Little CB, Smith MM. Curr RheumatoloRev 2008;4:175-182.

Disclosure of Interest: None declared DOI: 10.1136/annrheumdis-2018-eular.2610 